\title{
Building Students' Characters Through Character Education and Religiousity Values in Syair Kitab Ta'lim Muta'allim
}

\author{
Imron Amrullah $^{1, a)}$, Imayah ${ }^{1)}$ \\ 'Universitas Dr. Soetomo, Surabaya, Indonesia \\ E-mail: a)imron.amrullah@unitomo.ac.id
}

\begin{abstract}
This study examines the verses contained in the book Ta'lim Muta'allim to participate in the construction of student character. The source of data in this study is the Ta'lim Muta'allim book poetry which is relevant to the development of student character, character education and religiosity from the poetry of Talim Muta 'allim's book. The results of this study were (1) the value of character education consists of tips and ways to respect the teacher, to be humble, to talk a little and not to be arrogant. While acquired religiosity, among others, commands prayer, resigns, prays, begs for pleasure, obeys (obeys) and stays away from immorality. The results of the data analysis are recommended for those seeking knowledge so that the knowledge gained is useful to them and to others.
\end{abstract}

Keywords: kitab Ta'lim Muta'allim, character education, religiousity

\begin{abstract}
Abstrak
Penelitian ini mengkaji syair yang terdapat dalam kitab Ta'lim Muta'allim untuk ikut serta membangun karakter siswa. Sumber data dalam penelitian ini adalah syair dalam kitab Ta'lim Muta'allim yang relevan terhadap pembangunan karakter siswa, sedangkan datanya berupa informasi yang diperoleh dari frasa, kata, atau kalimat yang mengandung nilai pendidikan karakter dan religiusitas yang berasal dari syair dalam kitab Talim Muta'allim. Temuan yang diperoleh dari penelitian ini terdiri dari (1) nilai pendidikan karakter yang terdiri dari anjuran serta cara menghormati guru, rendah hati, sedikit berbicara, serta tidak memiliki sifat sombong; dan (2) nilai religiusitas, yaitu melakukan perintah salat, tawakal, berdoa, memohon rida, taat (patuh), dan menjauhi maksiat. Hal yang didapat dari analisis data tersebut dianjurkan bagi seseorang yang sedang mencari ilmu agar ilmu yang didapat bermanfaat bagi diri sendiri dan orang lain.
\end{abstract}

Kata kunci: kitab Ta'lim Muta'allim, pendidikan karakter, religiusitas 


\section{PENDAHULUAN}

Syair yang terkandung dalam kitab Ta'lim Muta'allim memiliki pesan yang tinggi terhadap orang yang mencari ilmu secara khusus dan secara umum pada kehidupan semua orang. Pesan-pesan tersebut memiliki pengaruh besar terhadap pembentukan karakter dan kesuksesan masa depan seorang siswa. Oleh sebab itu, kajian terhadap syair dalam kitab Ta'lim Muta 'allim perlu dilakukan untuk membentuk karakter seorang pencari ilmu sebagai salah satu bekal untuk kehidupan ke depannya. Syair sendiri menurut Teeuw (1984) merupakan kata yang berakar dari bahasa Arab syi'ir yang berarti puisi.

Syair-syair dalam kitab Ta'lim Muta'allim menjelaskan metode-metode dalam belajar, metode belajar cara bersikap terhadap guru, serta pembentuk karakter. Pembentuk karakter yang ditekankan dalam syair diperuntukkan untuk membentuk karakter seorang murid terhadap gurunya selaku perantara mengalirkan ilmu pengetahuan. Pendidikan karakter menjadi menjadi nilai pokok bagi seorang yan mencari ilmu karena perkembangan dalam diri antara aspek logika dan kerohanian harus berimbang. Keseimbangan dua hal tersebut memberikan dampak yang besar bagi perkembangan diri seorang pencari ilmu.

Pendidikan karakter menurut Latif (2009) merupakan induk dari istilah yang mendeskripsikan segala aspek pengajaran dan pembelajaran bagi perkembangan individu seseorang. Payung istilah ini membawahi penalaran moral/pengembangan kognitif, pembelajaran sosial dan emosional, pendidikan moral, pendidikan keterampilan hidup, pendidikan kesehatan, pencegahan kekerasan, resolusi konflik, serta filsafat etik/moral. Pendidikan karakter menjadi alternatif pemecah masalah dan membendung runtuhnya karakter dan dan budaya Indonesia (Wardani dan Suhita, 2018; Purwahida, 2017; Purwahida, 2018; Suhita \& Purwahida, 2018). Ada dua aspek menurut Prawira (2018) yang dapat membuat karakter seseorang berubah, yaitu faktor diri sendiri dan faktor lingkungan. Ainiyah (2013) menyatakan dalam temuannya, pendidikan karakter perlu ditanam sejak kecil melalui pendidikan agama Islam. Hal itu sejalan dengan penelitian yang dilakukan Aini (2014) bahwa pendidikan karakter harus dilakukan sejak dini berlandaskan hadits dan Quran.

Syair dalam kitab Ta'lim Muta'allim juga mengandung nilai religiusitas yang memberikan keseimbangan perkembangan jasmani dan rohani. Perkembangan mental merupakan sebuah keniscayaan bagi manusia khususnya remaja yang sedang mencari ilmu. Religiusitas menurut Aviyah dan Farid (2014) berkaitan dengan kontrol diri dengan kecenderungan kenakalan remaja. Ibadiyah dan Imayah (2018) menyatakan religiusitas merupakan keyakinan yang dimiliki oleh manusia untuk melakukan hal yang bersifat baik serta memperjelas batas-batas yang telah ditentukan.

Menurut Jalaluddin (2002) akar kata religi adalah religare yang asal katanya religio dari bahasa latin yang berarti mengikat. Religi (agama) memiliki aturan-aturan dan kewajiban yang harus dilaksanakan yang berfungsi untuk mengikat dan mengutuhkan diri seseorang atau sekelompok orang dalam hubungannya dengan Tuhan, sesama manusia dan alam sekitarnya. Anshari (1986) mengartikan religi, agama atau din sebagai sistem tata keyakinan atau tata keimanan atas dasar sesuatu yang mutlak di luar diri manusia dan merupakan suatu sistem ritus (tata peribadatan) manusia kepada yang dianggap mutlak, serta sistem norma yang mengatur hubungan manusia dengan manusia, manusia dengan alam lainnya dengan tata keimanan dan taata peribadatan yang telah dimaksud. 
Menurut Nashori (dalam Reza, 2013) religiusitas meliputi sejauh pengetahuan, kekokohan keyakinan, rutinitas pelaksanaan ibadah dan kaidah, serta penghayatan yang dalam atas agama yang dianut. Lebih lanjut, dalam religiusitas terdapat lima aspek, pertama akidah, Kedua syariah, Ketiga akhlak, Keempat pengetahuan agama, Kelima penghayatan. Aspek religiusitas dan pendidikan karakter dalam diri seseorang khususnya bagi orang yang sedang mencari ilmu harus benar-benar diperhatikan. Dua hal tersebut merupakan satu kesatuan yang tidak bisa dipisahkan antara satu sama lain. Seseorang yang sedang mencari ilmu yang memiliki keunggulan dalam aspek perkembangan karakter, harus mendalami aspek religiusitas yang tinggi pula agar terjadi keseimbangan antara perkembangan rasionalitas dan religiusitas. Oleh sebab itu, penelitian ini bertujuan untuk mengkaji syair aspek nilai pendidikan karakter dan religiusitas dalam kitab Ta'lim Muta'allim. Hal itu sesuai dengan temuan yang diperoleh oleh Kosasih (2013) dan Suhartatik (2018) bahwa pengajaran sastra dapat meningkatkan karakter siswa.

\section{METODE PENELITIAN}

Data dalam penelitian ini berupa frase, kata, atau kalimat yang mengandung nilai pendidikan karakter dan religiusitas yang berasal dari syair dalam kitab Ta'lim Muta'allim. Syair dalam kitab tersebut berbahasa Arab, sehingga perlu untuk diterjemahkan. Teknik terjemahan yang dijadikan acuan pada penelitian ini adalah konsep terjemahan Luther dan Nida seperti yang dijelaskan dalam Sudikan (2001) bahwa penerjemah harus mampu (1) mengalihkan aturan-aturan kata, untuk itu proses terjemahan harus memperhatikan pola-pola bahasa Arab sebagai bahasa teks syair dalam kitab Ta'lim Muta'allim; (2) menggunakan kata bantu; (3) menggunakan kata penghubung bila diperlukan; (4) tidak memasukkan kata atau padanan kata, yang tidak sesuai dengan kata asli teks; (5) menggunakan frase-frase teks asli syair dalam kitab Ta'lim Muta'allim; (6) mampu mengamati ragam dan gaya bahasa sumber; (7) pengetahuan terhadap bahasa Arab yang memadai; (8) mampu memahami isi pesan dalam teks; (9) harus memperhatikan kehalusan makna dan nilai emotif tertentu dari kosa kata teks serta gaya bahasa yang akan dapat menentukan cita rasa pesan yang disampaikan.

Pengumpulan data dalam penelitian ini menggunakan teknik dokumentasi. Dokumen menurut Moleong (1991) adalah setiap bahan tertulis ataupun film, lain dari record, yang tidak dipersiapkan karena adanya permintaan seorang penyidik. Sejalan dengan hal itu, tahap yang ditempuh, yaitu: pertama, menerjemahkan ke dalam bahasa Indonesia. Kedua, membaca dan memahami bahasa syair dan diteliti dengan mengaitkan pengalaman secara berulang-ulang sesuai dengan permasalahan. Ketiga, menentukan dan menginventarisasi syair sesuai dengan permasalahan.

Teknik analisis data penelitian ini menggunakan teknik analisis deskriptif. Teknik analisis deskriptif yang mendiskripsikan data dengan apa adanya sehingga menimbulkan kejelasan dan kemudahan bagi pembaca. Data yang diperoleh dalam penelitian ini sifatnya data kualitatif. Satoto dalam Setyani (2008) menyatakan bahwa data kualitatif merupakan data yang tidak berwujud angka-angka, melainkan uraian atau pernyataan-pernyataan. Dalam proses analisis data kualitatif melewati empat tahapan yaitu, (1) tahap interpretasi (penafsiran); (2) tahap deskripsi; (3) tahap analisis; (4) tahap evaluasi. 


\section{HASIL DAN PEMBAHASAN}

Hasil temuan pada penelitian ini akan dibahas berdasarkan nilai pendidikan karakter dan nilai religiusitas pada syair Kitab Ta'lim Muta'allim.

\section{Nilai Pendidikan Karakter}

Nilai pendidikan karakter pada syair Kitab Ta'lim Muta'allim dibahas berdasarkan nilai menghormati guru, rendah hati, sedikit bicara, dan tidak sombong.

\section{Menghormati Guru}

Guru adalah manusia yang kehidupannya diciptakan Allah SWT untuk melayani orang lain. Oleh sebab itu, orang yang harus dihormati setelah orang tua adalah guru, karena dengan ilmu pengetahuan yang diberi guru kita bisa mengetahui dan memahami isi alam yang sebelumnya kita tidak mengetahui. Seperti kutipan syair berikut.

Ra'aytu ahaqqal haqqi haqqal muallimi, Wa aujabahu hifzan ala kulli muslimin. Laqad haqqa ayyuhda ilaihi karamatan, Lita'limi harfin wahidin alfu dirhamin.

Menurutku hak yang paling utama adalah hak guru, Dan hak-hak itu wajib dijaga bagi setiap muslim.

Sungguh dia berhak diberi kemuliaan, Setiap ia mengajar satu huruf, tak cukup memberinya seribu dirham.

Kutipan syair di atas menyampaikan bahwa salah satu cara menghormati ilmu adalah meghormati guru. Sayyidina Ali R.A. menyampaikan, "Aku adalah hamba sahaya bagi orang-orang yang mengajarku, walaupun satu huruf saja. Bila ia bermaksud menjualku, maka ia bisa menjualku. Apabila dia bermaksud memerdekakanku, maka ia bisa memerdekakanku. Dan apabila ia bermaksud memperbudakku, maka ia bisa memperbudakku." Seorang guru menjadi tuan bagi muridnya sehingga kerelaan guru bisa menentukan masa depan seorang murid.

Satu huruf yang diajarkan oleh seorang guru merupakan satu tonggak dalam kehidupan manusia untuk mengetahui banyak hal. Oleh sebab itu, seorang murid harus menghormati guru layaknya menghormati kedua orang tua. Guru yang mengajarkan ilmu agama menjadi bapak seorang murid dalam aspek keagamaan, begitu juga dengan disiplin ilmu lainnya. Ada berbagai cara untuk menghormati seorang guru, antara lain berjalan dengan pelan di depannya, tidak duduk di tempatnya, tidak memulai percakapan dengannya kecuali atas seizinnya, tidak memperbanyak bicara di sampingnya, tidak menanyakan sesuatu ketika ia sudah bosan, menjaga waktu dan tidak mengetuk pintu rumah atau kamarnya, tetapi harus menunggu sampai ia keluar. Namun, apabila guru tidak dihormati maka ilmu yang diperoleh tidak akan bermanfaat, seperti yang tertulis dalam syair berikut.

Innal muallima wattabiba kila huma, La yansahani iza huma lam yukrama. Fasbir lida'ika injafauta tabibaha,Waqna' bijahlika injafauta mu'alliman.

Sesungguhnya guru dan dokter, Tidak akan berguna nasehatnya bila tidak dihormati. 
Bersabarlah dengan penyakitmu bila kamu menentang dokter, Dan bersabarlah kamu dengan kebodohanmu bila kamu menentang guru.

Menghormati seorang guru menjadi hal yang mutlak dilakukan oleh seorang murid dengan tujuan untuk mengapresiasi orang yang menjadi perantara Allah Swt dalam menyampaikan ilmu pengetahuan. Posisi seorang guru memiliki peran penting dalam keberlangsungan kehidupan yang penuh dengan wawasan serta berbagai disiplin ilmu yang terus dibagikan kepada orang lain. Oleh sebab itu, apabila seorang murid tidak menghargai guru yang sudah memberikan berbagai wawasan keilmuan, maka ilmu murid tersebut tidak akan bermanfaat bagi dirinya sendiri serta bagi orang lain.

\section{Rendah Hati}

Orang yang memiliki ilmu tinggi memiliki kecendrungan untuk rendah hati. Rendah hati memiliki tautan dari sikap mau mendengarkan pendapat orang lain karena salah satu ciri-ciri orang yang rendah hati adalah mau mendengarkan pendapat, kritik, serta saran dari orang lain. Tuhan menciptakan dua telinga dan satu mulut menjadi cerminan untuk lebih banyak mendengar daripada berbicara. Mendengarkan seringkali menguatkan orang yang lagi mengalami kesedihan atau kesulitan. Harus diakui pekerjaan mendengarkan memang dilakukan bukan dengan perasaan suka cita, tapi hampir semua orang lebih suka berbicara dari pada mendengarkan. Oleh sebab itu, mendengarkan adalah sifat dari orang yang bertaqwa seperti kutipan syair berikut.

\section{Innat tawaddu'a min khisalil muttaqi, Wabihit taqiyyu ilal ma ali yartaqi.}

Rendah hati adalah sikap orang yang bertakwa dan kelak akan mendapat derajat yang tinggi.

Sikap rendah hati mengharuskan manusia membuang ego jauh-jauh. Hal ini kadang bagi sebagian orang sangat sulit dilakukan. Terdapat berbagai macam ego, antara lain adalah ego ingin menonjol, ingin dominan, ego ingin lebih dikenal ataupun ego ingin selalu didengar dan diperhatikan orang lain. Ego-ego ini akan sulit dihilangkan jika kita tidak mempunyai keinginan untuk berubah dari yang bersikap sombong mau menang sendiri berubah menjadi bersikap rendah hati. Jika kita lihat dalam kehidupan sehari-hari, sifat orang yang tidak rendah hati, di antaranya adalah tidak bisa menerima kritikan walaupun itu sesuatu yang konstruktif. Mendengarkan akan lebih bermanfaat daripada orang yang banyak berbicara. Dengan mendengarkan, seseorang akan mengetahui kekurangan dan kelebihan yang ada dalam dirinya.

\section{Sedikit Bicara}

Berbicara dalam dunia pendidikan sangat penting untuk menyampaikan pendapat atau mengekslorasi ilmu yang diperoleh dalam kehidupan sehari-hari. Berbicara dapat mencerminkan kualitas diri seseorang. Namun, apabila seseorang terlalu banyak berbicara mencerminkan kedangkalan ilmu pengetahuannya, seperti pepatah mengatakan "Tong kosong nyaring bunyinya". Apabila sedikit bicara seseorang, akan memperlihatkan tingginya kualitas ilmu pengetahuannya seperti yang terdapat dalam syair berikut. 
Iza tamma aqlul mar'i qalla kalamuhu, Wa ayqin bihumqil mar'i inkana miksaran.

Apabila orang yang telah sempurna maka akan sedikit bicaranya dan apabila seseorang banyak bicara maka yakinlah akan kedunguannya.

Berdasarkan syair di atas, dapat diketahui bahwa seseorang yang alim akan sedikit berbicara dan orang yang banyak bicara akan memperlihatkan kebodohannya. Banyak bicara memberikan peluang untuk salah apabila tidak diiringi dengan rasa mawas diri. Orang yang memiliki ilmu pengetahuan secara mendalam cenderung berbicara sedikit karena memiliki sudut pandang luas sehingga paham secara keseluruhan terhadap apa yang dilihat. Sebaliknya, orang yang banyak bicara cenderung hanya memiliki satu sudut pandang dan meyakini bahwa sudut yang dimiliki merupakan sudut pandang yang paling benar.

Berbicara akan menjadi perhiasan bagi manusia apabila yang dibicarakan bermanfaat bagi diri sendiri dan orang lain. Namun, ketika yang dibicarakan tidak memberikan manfaat dan cenderung berbicara yang buruk. Oleh karena itu, berbicara yang demikian harus dihindari, seperti bunyi syair berikut.

\section{Annutqu zaynun wassukutu salamatun, Fa iza nataqta fala takun miksaran. Ma innadimta alas sukutimarratan, Walaqad nadimta alal kalami miraran.}

Berbicara adalah hiasan dan diam adalah selamat, bila kamu berbicara jangan berlebihan.

Penyesalan karena diam hanyalah sekali, tetapi penyesalan karena ucapan akan berkali-kali.

Dari kutipan syair di atas, diketahui bahwa penyesalan orang yang berbicara dan penyesalan orang yang diam sangat berbeda. Orang yang terlanjur mengeluarkan pernyataan akan lebih berlipat-lipat penyesalannya dibanding orang yang belum mengeluarkan pernyataannya. Orang yang terlanjur berbicara kepada orang lain maka bahan yang dibicarakan akan melekat di telinga orang yang mendengarkan, sehingga apabila yang dibicarakan itu hal yang salah maka akan menjadi nilai negatif bagi yang menyampaikan pembicaraan itu dan penyesalanlah yang akan dihadapinya. Berbeda dengan orang yang diam dan berbicara seperlunya, orang itu akan lebih terlihat bijaksana dan berwibawa. Oleh sebab itu, sebelum berbicara haruslah dipikirkan terlebih dahulu agar apa yang akan dibicarakan benar karena perkataan itu bagaikan anak panah, sehingga harus dipikirkan terlebih dahulu agar tepat pada sasarannya.

\section{Tidak Sombong}

Sifat sombong adalah kebalikan dari rendah hati yang harus dihindari karena sifat sombong menghabiskan amal kebaikan kita sama halnya dengan api menghabiskan kayu kering. Sifat sombong tidak boleh dimiliki manusia, khususnya para pencari ilmu karena hanya Allah SWT yang boleh sombong. Banyak sejarah mengatakan kalau sifat sombong akan merusak tatanan dalam diri seseorang, keluarga, masyarakat, dan negara. Contoh diri seseorang rusak karena sombong adalah Qarun yang ditenggelamkan bersama semua hartanya ke dalam bumi dan Firaun yang ditenggelamkan ke dalam Laut 
Merah oleh Allah SWT, itu semua karena sifat sombong.

Para pelajar diharapkan menjauhi sifat sombong karena ilmu pengetahuan tidak akan tertanam pada individu yang sombong, sebagaimana kutipan syair berikut ini.

\section{Walkibriya'u lirabbina sifatun bihi, Makhsusatun Fatajannabuha wattaqi. Al ilmu harbun lil muta'ali, Kassaili harbun lilmakanil ali.}

Kesombongan adalah sifat yang hanya menjadi milik Tuhan kita, maka jauhilah dan hindarilah.

Ilmu itu musuh bagi orang yang sombong, tinggi hati, sebagaimana air bah yang menenggelamkan tempat yang tinggi.

Sombong adalah sifat keji yang harus dihindari daripada tersemat dalam diri manusia, sifat sombonglah yang akan mencetus nilai-nilai negatif pada diri seseorang dan kehidupan bermasyarakat. Sombong merupakan satu perasaan hasil kombinasi dari sifat $u j u b$, takabur, egois, dan suka pamer. Sombong lahir dari dalam hati manusia lantaran mempunyai kelibihan harta, pangkat, ilmu, rupa, kekuatan fisik, dan lain sebagainya.

\section{Nilai Religiusitas}

Hidup dalam keberagamaan adalah manifestasi dari keniscayaan eksistensi dan kehadiran manusia sebagai ciptaan makhluk Tuhan. Dalam keberagamaan, manusia menyatakan sifat kemakhlukannya yang selalu membutuhkan dan tergantung pada $\mathrm{Al}$ Khalik, yang terwujud dalam sikap aslama, yaitu penyerahan dan pemasrahan diri kepada Tuhan. Kepasrahan pada dasarnya merupakan inti atau ruh, bukan saja bagi hidup keberagamaan, melainkan juga bagi hakikat keberadaan hidup manusia. Oleh karena itu, hubungan dengan Tuhan tidak bisa sekedar dilakukan dengan cara ritual yang bersifat formal dan memenuhi rutinitas, sementara kering dari pemahaman dan penghayatan akan substansi ritual itu sendiri. Hubungan dengan Tuhan harus dimaknai sebagai proses sadar untuk pembentukan kepribadian pemupukan kualitas diri. Hubungan keberagamaan demikianlah yang mampu mengantarkan pelakunya kearah peningkatan kesadaran berketuhanan (Mastuhu, 2000).

\section{Perintah Salat}

Manusia diciptakan oleh Allah SWT tidak lain hanya untuk menyembah-Nya yang diwujudkan dalam kehidupan sehari-hari yaitu berupa salat. Salat merujuk kepada ritual ibadah pemeluk agama Islam. Menurut syariat Islam, praktik salat harus sesuai dengan segala petunjuk tata cara Rasulullah SAW sebagai figur penyebar agama dan perintah Allah SWT. Rasulullah SAW bersabda, Salatlah kalian sesuai dengan apa yang kalian lihat aku mempraktikkannya. Fungsi salat selain menyembah dan mendekatkan diri kepada Tuhan juga untuk mencegah diri dari hal yang negatif karena manusia tidak akan bisa mencegahnya sendiri tanpa lindungan dari Allah SWT. Salat sendiri diwajibkan sejak Nabi Muhammad SAW melakukan Isra' Mi'raj. Berikut kutipan syairnya.

\section{Kun lil awamiri wannawahi hafizan, Wa alassalati muwaziban wa muhafitan.}


Jadilah orang yang mengamalkan perintah dan menjauhi larangan, terhadap salat selalu tak pernah berhenti melakukan.

Pada kutipan syair di atas, terdapat pesan tersurat bagi orang yang menuntut ilmu dan orang Islam pada umumnya harus melaksanakan perintah serta menjauhi larangan Allah SWT, khususnya perintah untuk salat lima waktu. Agama memang sangat menekankan kepada setiap orang Islam untuk tidak meninggalkan salat karena salat adalah tiang agama, sebagaimana Nabi Muhammad SAW bersabda bahwa "Shalat merupakan tiang agama". Oleh sebab itu, apabila orang muslim sudah meninggalkan salat, secara otomatis ibadah yang lainnya tidak akan optimal. Bagi orang muslim salat sangatlah penting perannya dalam keberagamaan karena dengan melaksanakan salat kita telah membangun pilar-pilar keagamaan secara kokoh. Pelaksanaan salat tidak mengenal status sosial dan ekonomi, semua setara dan sama dalam bentuk sujud menghadap Allah SWT.

Hadis Nabi Muhammad SAW telah memberikan peringatan keras kepada orang yang suka meninggalkan salat dan pada hari kiamat akan disandingkan bersama dengan orang-orang laknat. Hal tersebut disebutkan dalam hadis berikut, "Barangsiapa yang menjaga salat maka ia menjadi cahaya, bukti dan keselamatan baginya pada hari kiamat dan barang siapa yang tidak menjaganya maka ia tidak mendapatkan cahaya, bukti dan keselamatan dan pada hari kiamat ia akan bersama Qarun, Fir'aun, Haman dan Ubay bin Khalaf."

\section{Tawakal}

Sifat kedua yang harus diakukan seseorang setelah berusaha dalam mencapai citacita adalah tawakal. Tawakal adalah sikap memasrahkan diri kepada Allah SWT atas apa yang akan terjadi setelah melakukan suatu usaha karena memang tugas makhluk itu hanya sebatas berusaha sekuat tenaga dan hasilnya merupakan wewenang Tuhan semesta alam.

Orang yang mencari ilmu (siswa, santri, mahasiswa, dan lain-lain) telah diberi jaminan kesejahteraan rezeki oleh Allah SWT dalam hidupnya karena orang yang mencari ilmu menjadi salah satu kriteria mujahid fi sabilillah. Oleh karena itu, para pencari ilmu jangan khawatir atas rezeki karena Allah SWT mempunyai banyak cara untuk memberikan rezeki, seperti yang terdapat dalam syair berikut.

\section{Da'il makarima la tarhal libughyatiha, Waq'ud fainnaka antat ta iimul kasi.}

Tinggalkan kemuliaan, jangan kau pergi untuk meraihnya, duduklah saja, maka kamu akan makan dan berpakaian.

Dalam belajar penuntut ilmu haruslah bertawakkal kepada Allah dan jangan tergoda oleh urusan-urusan rizki. Sebagaimana sabda Rasulullah, "Barang siapa mempelajari agama, Allah akan mencukupi kebutuhan dan memberinya rizki dari suatu jalan yang tidak disangka-sangka". Seseorang yang tergoda oleh urusan rezeki tidak gampang menghilangkannya demi kemuliaan akhlak dan urusan-urusan yang bernilai tinggi.

Orang yang bijaksana hendaknya tidak digelisahkan oleh urusan duniawi karena gelisah dan sedih tidak akan bisa mengelakkan musibah. Bahkan membahayakan hati, 
akal, badan dan merusak perbuatan-perbuatan yang baik. Oleh karena itu, penuntut ilmu hendaknya berusaha sekuat mungkin untuk mengurangi atau meninggalkan urusanurusan duniawi.

\section{Berdoa}

Berdoa adalah bentuk komunikasi, permohonan, dan pencurahan hati seorang makhluk terhadap Allah SWT. Doa menjadi alat komunikasi antara manusia dan Allah SWT karena berdoa akan menjadi komunikasi secara batin dan penyatuan antara makhluk dan tuhannya, sedangkan doa sebagai ungkapan permohonan dan pencurahan karena Allah SWT telah berfirman, "Berdoalah (mintalah) kepada-Ku, niscaya akan Aku kabulkan" dan perhatikan syair berikut.

Wa as'al ilahaka hifan hiftika raghiban, Fi fadlihi fallahu khairun hafizan.

Mintalah kepada Allah agar kuat hafalan karena cinta kepada keutamaannya, Allah adalah sebaik-baik pelindung.

Kutipan syair dan firman Allah di atas, dapat diketahui bahwa manusia diwajibkan berdoa dan minta perlindungan kepada Allah SWT. Dalam berdoa dianjurkan untuk bersuara tidak dianjurkan hanya dikatakan dalam hati karena Tuhan ingin mendengar suara merdu makhluk yang benar-benar memohon dan mengiba-iba atas pemberian Allah SWT. Orang yang hanya berdoa dalam hati kurang optimal dalam meminta, sama halnya dengan orang yang hanya berkeinginan saja dan tidak termasuk doa karena doa adalah keinginan yang diucapkan dan ditujukan kepada Allah SWT.

\section{Taat}

Taat merupakan pekerjaan setia seorang murid pada gurunya dan seorang hamba kepada Tuhannya. Taat merupakan pemujaan yang sangat berharga yang dilakukan seorang murid terhadap gurunya dan seorang hamba terhadap Tuhannya. Dengan demikian, jika seseorang sudah bisa taat (patuh) berarti orang tersebut sudah mampu membunuh sifat mendahulukan kepentingan pribadi dalam menjalani proses spiritualnya.

Patuh merupakan salah satu jalan spiritual yang sangat sulit dilakukan. Sebab, ketika seseorang sudah mengetahui sebagian ilmu, dirinya merasa mampu untuk mandiri dan sudah tidak membutuhkan bimbingan maupun pada perintah guru atau petunjuk dari tuhannya. Padahal, sebenarnya individu tersebut belum tahu banyak hal tentang dunia dan isinya.

Menjalani kehidupan sebagai seorang murid atau seorang hamba diwajibkan untuk taat dan tidak bermalas-malasan, seperti kutipan syair berikut.

Ati'u wajidddu wala taksalu, Wa'antum ila rabikum tarja'una.

Taatlah, bersemangatlah dan jangan bermalas-malasan, Kalian akan kembali kepada Tuhanmu.

Taat dan patuh dapat diartikan sebagai disiplin, tertib, dan teratur. Umat yang taat 
dan patuh terhadap ajaran agama, berarti umat yang secara disiplin, tertib, dan teratur menjalankan ibadah dan takwa. Takwa terhadap ajaran agama memiliki arti patuh terhadap ajaran-Nya dan menjahui segala larangan-Nya. Menjalankan perintahnya seperti Tri Sandhya tiga kali sehari untuk umat Hindu dan menjahui larangannya seperti tidak memfitnah, berbohong, korupsi, memperkosa dan lain sebagainya.

Seorang pelajar ditekankan untuk belajar patuh karena kalau seorang pelajar sudah mampu patuh maka Tuhan akan mempercayakan untuk memerintahkan. Belajar menjadi pelajar yang baik, maka suatu saat nanti akan menjadi guru. Hindari hayalan atau perasaan sudah mandiri dan tidak butuh pada guru karena hal tersebut merupakan mental budak.

\section{Memohon Rida}

Kata rida berasal dari bahasa Arab yang makna harfiahnya mengandung pengertian senang, suka, rela, menerima dengan sepenuh hati, serta menyetujui secara penuh. Lawan kata rida adalah benci atau tidak senang. Kata rida ini lazim dihubungkan dengan eksistensi Tuhan dan manusia seperti Allah SWT rida kepada orang-orang yang beriman dan beramal soleh, serta dalam kehidupan manusia seperti seorang ibu rida anaknya merantau untuk menuntut ilmu. Rida erat kaitannya dengan sikap dan pemahaman manusia atas karunia dan nikmat Allah.

Rida Allah adalah simbol dari diterimanya pekerjaan yang dilakukan seorang hamba kepada tuhannya, baik dari segi syarat dan rukunnya maupun dari aspek keberagamaan yang lainnya. Dalam mencari ilmu, setiap pekerjaan yang akan dilakukan pelajar dituntut untuk memohon rida kepada Tuhannya seperti kutipan syair berikut.

\section{Taraktunnauma rabbi fillayali, Li ajli ridaka ya maulal mawali.}

Ya tuhanku, kutinggalkan tidur di malam hari, untuk mendapatkan ridla-Mu, wahai Tuhan bagi segala tuan.

Kutipan syair di atas, dapat diletahui bahwa rida menuntut adanya usaha aktif, misalnya tidak tidur malam untuk beribadah. Itulah aspek yang berbeda dengan sikap pasrah yang menerima kenyataan begitu saja tanpa ada usaha untuk mengubahnya. Walaupun di dalam rida terdapat makna yang hampir sama dengan pasrah yaitu menerima dengan lapang dada suatu perkara, inividu tetap dituntut adanya usaha untuk mencapai suatu target yang diinginkan atau mengubah kondisi yang ada. Rida terhadap aturan Allah seperti perintah mengeluarkan zakat, bukan berarti hanya mengakui itu adalah aturan Allah melainkan disertai dengan usaha untuk menunaikannya. Dengan kata lain, pasrah yang tidak diimbangi dengan mawas diri akan melahirkan sikap fatalisme, sedangkan rida justru mengajak orang untuk optimistis.

\section{Menjauhi Maksiat}

Salah satu ujian terberat para pencari ilmu adalah maksiat. Maksiat yang paling sering dan tidak bisa dihindari adalah maksiat mata, misalnya melihat aurat wanita yang bukan mahram. Banyak dampak negatif yang ditimbulkan oleh maksiat, di antaranya cepat lupa, membutakan mata hati, dan lain sebagainya.

Bagi pelajar, hal yang paling utama adalah mengingat materi yang telah 
didapatkan dari seorang guru karena kalau pengetahuan yang telah diperoleh sudah tidak diingat lagi, maka sia-sialah usaha belajarnya. Salah satu hal yang sangat membuat orang lupa adalah berbuat maksiat, berikut kutipan syairnya.

Syakautu ila waki'in su'a hifzi, Fa'arsyadani ila tarkul ma'asi.

Fainnal hifza fadlun min ilahi, Wafadlullahi la yu'ta li asi.

Aku mengadu kapada imam Waki' tentang hafalanku yang lemah, lantas ia memberiku petunjuk agar meninggalkan maksiat.

Hafalan adalah pemberian dari Tuhan, sedang pemberian Tuhan tidaklah diberikan kepada orang yang bermaksiat.

Seperti yang diungkapkan pepatah Arab, "ilmu itu cahaya". Apabila ilmu pengetahuan adalah cahaya maka tidak mungkin masuk kepada orang yang berbuat maksiat, sangat sulit ilmu masuk kepada orang yang berbuat maksiat apalagi untuk mengingatnya. Ilmu pengetahuan adalah pemberian Tuhan, sehingga mustahil masuk kepada orang yang berbuat maksiat.

\section{KESIMPULAN}

Syair yang terdapat dalam Kitab Ta'lim Muta'allim memiliki kandungan nilai pendidikan karakter dan religiusitas yang dapat meningkatkan karakter siswa. Hal itu terdapat dalam data-data yang diperoleh melalui analisis data dalam kajian ini. Nilai pendidikan karakter yang terdiri dari anjuran serta cara menghormati guru, rendah hati, sedikit berbicara, serta tidak memiliki sifat sombong. Sementara itu, nilai religiusitas yang didapat antara lain melakukan perintah salat, tawakkal, berdoa, memohon rida, taat (patuh), dan menjauhi maksiat. Hal yang didapat dari analisis data tersebut dianjurkan bagi seseorang yang sedang mencari ilmu khususnya siswa agar ilmu yang didapat bermanfaat bagi diri sendiri dan orang lain.

\section{UCAPAN TERIMA KASIH}

Peneliti mengucapkan terima kasih kepada semua pihak yang telah membantu penelitian ini, baik bantuan moral ataupun materil.

\section{REFERENSI}

Aini, A.N. (2014). Pendidikan karakter untuk siswa SD dalam perspektif Islam. Jurnal Mimbar Sekolah Dasar, 1(1), 50-58. doi: dx.doi.org/10.17509/mimbarsd.v1i1.863

Ainiyah, N. (2013). Pembentukan karakter melalui pendidikan agama Islam. Jurnal AlUlum, $13 \quad$ (1), 25-38. $\quad$ Retrieved from https://journal.iaingorontalo.ac.id/index.php/au/article/view/179/159

Anshari, S.E. (1986). Wawasan Islam. Jakarta: PT Rajawali Press.

Aviyah, E., \& Farid, M. (2014). Religiusitas, kontrol diri, dan kenakalan remaja. 
Persona: Jurnal Psikologi Indonesia, 3(2), 126-129. doi: doi.org/10.30996/persona.v3i02.376

Ibadiyah, I., Imayah. (2018). Etika, estetika, dan religiusitas legenda dalam cerita Jokotole dan Dewi Ratnadi. Jurnal Ilmiah FONEMA: Jurnal Edukasi Bahasa dan Sastra Indonesia, 1(2), 122 - 137. doi: doi.org/10.25139/fn.v1i2.1239

Jalaluddin, R. (2002). Psikologi Islam. Jakarta: PT Raja Grafindo Persada.

Kosasih, E. (2013). Sastra klasik sebagai wahana efektif dalam pengembangan pendidikan karakter. Jurnal Pendidikan Bahasa dan Sastra (Journal of Language and Literature Education), 13(2), 225-236. doi: 10.17509/bs_jpbsp.v13i2.294

Latif, Y. (2009). Menyemai Karakter Bangsa: Budaya Kebangkitan Berbasis Kesastraan. Jakarta: Penerbit KOMPAS.

Mastuhu. (2000). Teologi Pendidikan Tauhid sebagai Paradigma Pendidikan Islam. Jakarta: Friska Agung Insani.

Moleong, L.J. (1991). Metodologi Penelitian Kualitatif. Bandung: Remaja Rosdakarya.

Prawira, S.D. (2018). Karakter tokoh utama pada novel Entrok karya Okky Madasari (Kajian Psikologi Sastra). Jurnal Ilmiah FONEMA: Jurnal Edukasi Bahasa dan Sastra Indonesia, 1,(1), 1-15. doi: doi.org/10.25139/fn.v1i1.1092

Purwahida, R. (2017). Interaksi sosial pada kumpulan cerpen Potongan Cerita di Kartu Pos karangan Agus Noor dan implikasinya terhadap pembelajaran sastra di SMA. Aksis: Jurnal Pendidikan Bahasa dan Sastra Indonesia 1(1). 118-134. doi: doi.org/10.21009/AKSIS.010107

Purwahida, R. (2018). Problematika Pengembangan Modul Pembelajaran Baca Tulis Anak Usia Sekolah Dasar. Aksis: Jurnal Pendidikan Bahasa dan Sastra Indonesia 2(1). 118-134. doi: doi.org/10.21009/AKSIS.020108

Reza, I.F. (2013). Hubungan antara religiusitas dengan moralitas pada remaja di Madrasah Aliyah (MA). Humanitas, X(2). doi: doi.org/10.26555/humanitas.v10i2.336

Setyani, B. (2008). Aspek Nilai dalam Kumpulan Puisi Anak-Anak Untuk Pak Harto karya Team Dokumentasi Presiden RI. (Skripsi). Universitas Dr. Soetomo, Surabaya.

Sudikan, S.Y. (2001). Metode Penelitian Kebudayaan. Surabaya: Unesa Unipress Citra Wacana.

Suhartatik. (2018). Makna Leksikal Bahasa Madura Keadaan Alam Nelayan di Pesisir Kepulauan Sumenep. Aksis: Jurnal Pendidikan Bahasa dan Sastra Indonesia 2(1). 107-126. doi: doi.org/10.21009/AKSIS.020107 
Suhita, S. \& Purwahida, R. (2018). Apresiasi Sastra Indonesia. Bandung: Remaja Rosdakarya.

Teeuw, A. (1984). Sastra dan Ilmu Sastra. Jakarta: Pustaka Jaya.

Wardani, Y.F., \& Suhita, S. (2018). Nilai Pendidikan Karakter dalam Novel Rindu Karangan Tere Liye: Tinjauan Psikologi Karakter. AKSIS: Jurnal Pendidikan Bahasa dan Sastra Indonesia, 2(2), 246-274. doi: doi.org/10.21009/AKSIS.020207 